\title{
CORRUPT LOCAL GOVERNMENT AS RESOURCE FARMERS: THE HELPING HAND AND THE GRABBING HAND
}

\author{
ENGIN DALGIC \\ NGO VAN LONG \\ CESIFO WORKING PAPER No. 1248 \\ CAtegory 1: Public Finance \\ JULY 2004 \\ An electronic version of the paper may be downloaded \\ - from the SSRN website: www.SSRN.com \\ - from the CESifo website: www.CESifo.de
}




\title{
CORRUPT LOCAL GOVERNMENT AS RESOURCE FARMERS: THE HELPING HAND AND THE GRABBING HAND
}

\begin{abstract}
We study the role of tax share and transparency of governance on growth and stagnation. A local government maximizes its private benefits using two activities. The first one consists of providing local public goods that help local firms to increase profits, thus enlarging tax revenue. The second one consists of extortion. We show that there is a threshold level of local government tax share, and a threshold level of transparency. Below these thresholds, the economy will stagnate and above them, the economy will achieve perpetual growth.

JEL Code: H41.
\end{abstract}

Keywords: corruption, growth, local government, tax share.

Engin Dalgic

Department of Economics

McGill University

855 Rue Sherbroke Ouest

Montreal, H3A $2 T 7$

Canada
Ngo Van Long

Economics, AS7-Level 5

5 Arts Link, Shaw Building

National University of Singapore

Singapore 117570

Singapore

ngo.long@mcgill.ca 


\section{Introduction}

Corruption can occur at several levels of government. Our interest is on factors that determine the pattern of corruption at the local government level. In this paper, we model a situation where a central government determines both the income tax rate and the share of tax revenue between the central government and the local governments, while the local governments seek to maximize their own private benefits, by engaging in two classes of activities. The first one consists of providing public goods to local private firms, because these public goods help the firms to make more profit, thus enlarging the tax base. The second one consists of extortionary activities, such as charging fees, protection money, etc., on local firms. We assume that either these extortionary activities escape the notice of the central government, or the latter is aware of them but does not have sufficient evidence to prosecute corrupt local government officials. The two classes of activities mentioned above may be called respectively the helping hand activities and the grabbing hand activities.

Olson $(1993,2000)$ distinguishes two types of bandits that correspond to the helping hand and the grabbing hand behaviour. A roving bandit seeks new preys and has no interest in the future development of the current preys. He wants to grabb as much as possible. A stationary bandit, on the other hand, cares about the future prosperity of the current preys, and this is the reason for the helping hand behaviour to co-exist with the grabbing hand behaviour ${ }^{1}$. Our view of corrupt local governments is that they exhibit both types of behaviour. Whether a local government puts more emphasis on the helping hand or on the grabbing hand depends on (a) the revenue share that the central government allows it to have, (b) the cost of hiding extortionary activities from the central government, and (c) the discount rate.

One may expect that when the central government raises its share of tax revenue, the local government may respond by reducing the level of its helping hand activities, and intensifies its grabbing hand activities. The long-term consequence of this shift of balance is a decrease in the tax base. Thus, the tax revenue of the central government, expressed as a function of the its tax share, has the inverted $U$ shaped. Such an outcome would be consistent with the view underlying the Laffer curve.

Our dynamic model contains several additional interesting results, especially those relating to growth and stagnation. First, there are two stationary equilibria. One of these (with a smaller steady state capital stock) has the saddlepoint stability property. The other stationary equilibrium (with a greater level of capital stock) is completely unstable. Second, a permanent increase in the central government's

\footnotetext{
${ }^{1}$ A related phenomenon is the optimal feeding of slaves, see Rees et al. (2003) for theory and empirical evidence.
} 
tax share will reduce the (stable) steady state capital stock, because it discourages the helping hand. The grabbing hand activity level increases initially, but eventually falls, because the new steady state stock is lower. Third, if the initial capital stock is below the unstable steady state stock, the optimal policy is to converge to the (lower) stable steady state stock, but if the initial capital stock exceeds the unstable steady state stock, it will be optimal to keep the grabbing activity level constant and increase the helping activity level steadily, causing the capital stock, and income, to increase without bound. The unstable steady state stock can be shown to be an increasing function of the central government 's tax share imposed by the central government, and a decreasing function of the degree of transparency of local government activities. It follows that, given any initial capital stock, there is a corresponding threshold level of central government tax share, with the property that if the tax share is higher than this threshold level, the economy starting with this initial stock will stagnate, and if the tax share is below the threshold level, the economy will achieve positive growth for ever. Similarly, given the initial capital stock, there is a threshold level of transparency of governance, i.e., the difficulty of hiding corruption. If the transparency is below the threshold level, the economy will stagnate, and if the transparency is greater than the threshold level, the economy will achieve positive growth for ever.

There are static models that address issues relating to self-serving local governments. Keen and Kotsogianis (2003) developed a model where the central government and the local governments compete in taxation. A section of their paper deals with the case where the central government is a Stackelberg leader. Chen (2003) examines the recentralization of tax in China, and argues that the central government of China did not take into account the possibility that an increase in central tax share may encourage the grabbing hand behaviour of local governments. However, unlike our dynamic model, those papers, being set in a static framework, cannot deal with issues such as perpetual growth versus stagnation.

The general topic of government corruption has been studied by many authors, but typically they use a static framework ${ }^{2}$. Dynamic analyses of corruption include the work of Tornell and Velasco (1992), and Tornell and Lane (1999). These papers do not deal with taxation issues ${ }^{3}$, nor with revenue sharing

\footnotetext{
${ }^{2}$ The view that policy makers are revenue-maximizing Leviathans has been forcefully expressed by many authors, see in particular Brennan and Buchanan (1977, 1980). More recent works include Basu et al. (1992), Schleifer and Vishny (1993), Mauro (1995), Frye and Schleifer (1997), Acemoglu and Verdier (2002), Ades and Di Tella (2002), Ni and Pham (2003).

${ }^{3}$ There is a large literature that deals with taxation issues in a dynamic framework. See, for example, Kemp et al. (1993), Long and Shimomura (2002), and references cited therein. However, these authors typically assume that governments are benevolent bodies rather than Leviathans.
} 
between the central government and the local government, nor with transparency of governance.

We begin our analysis with a static model, presented in Section 2. Our main contribution is the dynamic model, presented in Sections 3 to 7 . Some concluding remarks are offered in Section 8.

\section{A static model}

In this section, a static model of tax sharing and local government corruption is presented. We assume there are no interactions among local governments, so that, without loss of generality, we focus on the case where there are only two governments: a central government and a local government. The static setting can be interpreted as the situation where the local government acts as a roving bandit. The local government has only one shot at extracting as much as possible from the firms, and it is not concerned with the capital accumulation and the associated future benefits.

Let the local firms have the aggregate production function $Y(h, K)$, where $h$ is the flow of productivityenhancing public goods provided by the local government, and $K>0$ is the aggregate stock of capital.

We assume production function is strictlty concave and increasing in each argument, with

$$
Y_{h K}>0, \text { and } \lim _{h \rightarrow 0} Y_{h}(h, K)=\infty
$$

The local government takes as given the tax rate firms face, which is denoted by $v$, and the revenue share between itself and the central government, $1-\theta$ and $\theta$, respectively. We assume $0<v<1$ and $0 \leq \theta \leq 1$.

The local government, in addition to providing useful public goods, can extort money from the local firms through a costly process. Let $g \geq 0$ denote the amount of money extorted. Let the local government's cost of extortion be represented by $C(g)$. This cost includes the effort cost as well as the cost of covering up to avoid audits by the central government. We assume that $C(0)=0, C^{\prime}(g)>0$, $C^{\prime}(0)<1$ and $C^{\prime \prime}(g)>0$. The assumption $0 \leq C^{\prime}(0)<1$ implies that the level of grabbing will always be positive.

The objective of the local government is to maximize its private net benefits:

$$
\max _{g, h} B \equiv(1-\theta) v Y(h, K)-h+g-C(g)
$$

subject to

$$
(1-v) Y(h, K)-g \geq 0
$$




$$
h \geq 0 \text { and } g \geq 0
$$

The constraint (2) states that the amount extorted cannot exceed the local firms' after-tax income. The inequalities (2) and (3) define a feasible set $S$ which is a convex and non-empty subset of $R^{2}$ :

$$
S=\{(h, g) \geq(0,0): g \leq(1-v) Y(h, K)\}
$$

If we represent the set $S$ in the space $(h, g) \geq(0,0)$, where $h$ is measured along the horizontal axis, and $g$ along the vertical axis, we can see that the upper boundary of this set is the curve

$$
g=(1-v) Y(h, K)
$$

which is has the concave shape. Since the set $S$ has an interior, the Slater condition holds.

The Lagrangian function is:

$$
L=(1-\theta) v Y(h, K)-h+g-C(g)+\lambda_{1}((1-v) Y(h, K)-g)+\lambda_{2} g+\lambda_{3} h
$$

The first order conditions are:

$$
\begin{gathered}
\frac{\partial L}{\partial h}=(1-\theta) v Y_{h}-1+\lambda_{1}(1-v) Y_{h}+\lambda_{3}=0 \\
\frac{\partial L}{\partial g}=1-C^{\prime}(g)-\lambda_{1}+\lambda_{2}=0 \\
\lambda_{1} \geq 0,(1-v) Y(h, K)-g \geq 0 \text { and } \lambda_{1}[(1-v) Y(h, K)-g]=0 \\
\lambda_{2} \geq 0, g \geq 0 \text { and } \lambda_{2} g=0 \\
\lambda_{3} \geq 0, h \geq 0 \text { and } \lambda_{3} h=0 .
\end{gathered}
$$

Since the objective function is strictly concave, and the constraints are concave in $(h, g)$, the necessary conditions yield a unique global maximum. We now show that this unique solution $\left(h^{*}, g^{*}\right)$ may be in the interior of the feasible set $S$, or may be at the upper boundary of this set, i.e., a point on the curve $g=(1-v) Y(h, K)$.

First let us establish that, if $\theta<1$ and $K>0$, then at the optimum, $h^{*}>0$ and $g^{*}>0$. For suppose $h^{*}=0$. Then equation (4) would yield

$$
\left[(1-\theta) v+\lambda_{1}(1-v)\right] \infty+\lambda_{3}=1
$$

which is not possible. It follows that $h^{*}$ must be positive. Now suppose that $g^{*}=0$. Then $(1-$ $v) Y\left(h^{*}, K\right)-g^{*}=(1-v) Y\left(h^{*}, K\right)>0$, and hence $\lambda_{1}=0$. Substituting this result into equation (5) 
we get $1-C^{\prime}(0)+\lambda_{2}=0$ which yields $C^{\prime}(0)=1+\lambda_{2} \geq 1$. This is not possible because by assumption $C^{\prime}(0)<1$. It follows that $g^{*}$ must be positive.

Lemma S1: At the optimum, $\lambda_{2}=\lambda_{3}=0$ provided $\theta<1$. If $\theta=1$, then $h^{*}=0$.

We conclude that if $\theta<1$, the optimal point $\left(h^{*}, g^{*}\right)$ must be either an interior point of the feasible set $S$, or a point on the boundary curve $g=(1-v) Y(h, K)$. (Note that on this curve, all the after-tax profits of local firms are appropriated by the local government by extortion.)

\section{Case 1: Interior solution.}

At an interior solution, all the Lagrange multipliers are zero, and we get

$$
\begin{gathered}
(1-\theta) v Y_{h}(h, K)-1=0 \\
1-C^{\prime}(g)=0
\end{gathered}
$$

Let $\widehat{g}$ be the unique value of $g$ that satisfies $1-C^{\prime}(\widehat{g})=0$, that is

$$
\widehat{g}=\left(C^{\prime}\right)^{-1}(1)
$$

Let $\widehat{h}(K, v, \theta)$ be the unique solution of

$$
Y_{h}(\widehat{h}, K)=\frac{1}{(1-\theta) v}
$$

The pair $(\widehat{h}, \widehat{g})$ is the interior solution of problem (1) if and only if

$$
\left(C^{\prime}\right)^{-1}(1)<(1-v) Y(\widehat{h}(K, v, \theta), K)
$$

Comparative static results can be obtained by differentiating equation (7) totally:

$$
Y_{h h} d h+Y_{h K} d K=-\frac{1}{(1-\theta) v^{2}} d v+\frac{1}{(1-\theta)^{2} v} d \theta
$$

Thus

$$
\begin{gathered}
\frac{\partial \widehat{h}(K, v, \theta)}{\partial K}=-\frac{Y_{h K}}{Y_{h h}}>0 \\
\frac{\partial \widehat{h}(K, v, \theta)}{\partial v}=-\frac{1}{(1-\theta) v^{2} Y_{h h}}>0 \\
\frac{\partial \widehat{h}(K, v, \theta)}{\partial \theta}=\frac{1}{(1-\theta)^{2} v Y_{h h}}<0
\end{gathered}
$$

Thus we obtain the following proposition:

Proposition S1: If $\theta<1$ and condition (8) holds, the solution of the local government's optimization problem is an interior solution. In this case, small changes in the parameters $v, \theta$ and $K$ do 
not affect the level of its grabbing activities. An increase in the central government's tax share $\theta$ will reduce the level of the helping activities, while an increase in the capital stock $K$ or in the tax rate $v$ will increase it.

It should be noted that since an increase in $\theta$ will reduce $\widehat{h}$, a sufficiently large increase in $\theta$ will lead to a violation of condition (8) and move the optimal solution to the upper boundary of the feasible set $S$. (Similarly, a sufficiently large decrease in $v$ or $K$ may move the point $\widehat{h}(K, v, \theta)$ to such an extent that the optimal solution will be on the upper boundary of the feasible set.)

\section{Case 2: Boundary solution.}

If condition (8) fails to hold, then the solution occurs at the upper boundary of the feasible set $S$. In this case, the solution must satisfy the following pair of equations

$$
\begin{gathered}
(1-\theta) v Y_{h}-1+\left[1-C^{\prime}(g)\right](1-v) Y_{h}=0 \\
g=(1-v) Y(h, K)
\end{gathered}
$$

Substituting (10) into (9) and rearranging we get,

$$
\left\{(1-\theta) v+(1-v)\left[1-C^{\prime}((1-v) Y(h, K))\right]\right\} Y_{h}(h, K)=1
$$

Thus

$$
\frac{\partial h}{\partial \theta}=\frac{v Y_{h}}{Y_{h h}\left[(1-\theta) v-(1-v)\left(1-C^{\prime}(g)\right)\right]-Y_{h}^{2}(1-v)^{2} C^{\prime \prime}(g)}<0
$$

We differentiate equation (10) with respect to $\theta$ to get

$$
\frac{\partial g}{\partial \theta}=(1-v) Y_{h} \frac{\partial h}{\partial \theta}<0
$$

Proposition S2: Assume that $\theta<1$ and the central government tax share $\theta$ is sufficiently large, or $K$ and $v$ are sufficiently small, so that the local government's optimal solution is on the upper boundary of the feasible set. All the after-tax profits of local firms are appropriated by the local government by extortion. The level of helping hand activities declines with an increase in $\theta$, and the amount to be extorted from the local firms also declines with $\theta$.

To summarize, the helping hand $h$ is discouraged by decreases in the share of taxes received by the local government in both interior and corner solutions. The grabbing hand $g$ is unaffected by changes 
in $\theta$ in interior solutions. In the case of a boundary solution, the actual corruption is constrained by the total after-tax income of the firms, and an increase in $\theta$ (and the associated decline in $h$ ) decreases corruption in absolute value. But the proportion of after-tax income extracted illegally by the local government remains at 100 percent in this case.

\section{A dynamic model of growth and stagnation}

\subsection{Assumptions and notation}

A major drawback of the static model is that it cannot address issues such as perpetual growth and stagnation. In particular, static models cannot explain how a small change in parameter values (such as the central government's tax share, the local government's corruption ability, the level of government transparency) can turn a rapidly growing economy into a contracting economy. To deal with these issues, we develop and analyze a simple dynamic extension of the static model.

The local firms have an aggregate capital stock $K(t)$ at time $t$. This stock, together with the local government spending on public goods $h(t)$, yields a flow of taxable income

$$
Y(h(t), K(t))=h(t)^{\alpha} K(t)^{\beta} \text { where } \alpha>0, \beta>0 \text { and } \alpha+\beta \leq 1
$$

(In what follows, we often suppress the time argument for simplicity of notation.) The central government sets a constant tax rate $v<1$. Tax revenue is $v h^{\alpha} K^{\beta}$. The central government's share of this revenue is $\theta$, and $1-\theta$ is the local government's share.

The local government can also charge extortionary fees (of which the central government is vaguely aware, but cannot provide evidence for prosecution). We denote by $g(t)$ the total of these off-budget revenues at time $t$. (Here, the symbols $g$ and $h$ stand for the grabbing hand and the helping hand, respectively). The net benefit received by the local government at time $t$ is

$$
R(t)=(1-\theta) v h(t)^{\alpha} K(t)^{\beta}-h(t)+g(t)-C(g(t))
$$

where $C(g(t))$ denote the effort cost of extortion.

For simplicity, assume that the effort cost of extortion is quadratic

$$
C(g(t))=\varepsilon g(t)+\frac{1}{2} \gamma g(t)^{2} \text { where } \gamma>0 \text { and } 1>\varepsilon \geq 0
$$

The parameters $\varepsilon$ and $\gamma$ are measures of the costliness of performing (and hiding the evidence of) grabbing activities. (They may serve as proxies for the degree of transparency of local government activities; for any increase in transparency would increase the costs of hiding extortion.) 
The rate of growth of the capital stock is assumed to be

$$
\dot{K}(t)=s(1-v) h(t)^{\alpha} K(t)^{\beta}-g(t)
$$

where $s$ is the proportion of profits that businessmen allocate to capital formation. We assume that the extortion yields revenue only if the capital stock is positive. (When the capital stock is zero, extortion is fruitless).

The local government chooses the time paths of $g(t)$ and $h(t)$ to maximize

$$
\int_{0}^{\infty} R(t) e^{-r t} d t
$$

subject to the differential equation (12), the non-negativity constraints $g(t) \geq 0, h(t) \geq 0$, the initial condition $K(0)=K_{0}$ and

$$
\lim _{t \rightarrow \infty} K(t) \geq 0 .
$$

Here $r$ is the rate of discount, assumed to be positive.

\subsection{The Optimal Control Problem of the Local Government}

The current-value Hamiltonian is

$$
H=(1-\theta) v h(t)^{\alpha} K(t)^{\beta}-h(t)+(1-\varepsilon) g(t)-\frac{1}{2} \gamma g(t)^{2}+\psi(t)\left[s(1-v) h(t)^{\alpha} K(t)^{\beta}-g(t)\right]
$$

For $\psi(t) \geq 0$, the Hamiltonian is concave in the state and control variables. Thus any path $(\psi, K, g, h)$ that satisfies the necessary conditions and leads to a steady state $\left(K_{s s}, \psi_{s s}\right) \geq(0,0)$ is an optimal path, provided $\psi(t) \geq 0$ along that path ${ }^{4}$.

The necessary conditions consist of

(i) The maximality condition: the control variables must maximize $H$ for given $(K, \psi)$ :

$$
\begin{gathered}
\frac{\partial H}{\partial h}=\alpha h^{\alpha-1} K^{\beta}[v(1-\theta)+\psi s(1-v)]-1 \leq 0, h \geq 0 \text { and } h \frac{\partial H}{\partial h}=0 \\
\frac{\partial H}{\partial g}=(1-\varepsilon-\psi)-\gamma g \leq 0, g \geq 0 \text { and } g \frac{\partial H}{\partial g}=0
\end{gathered}
$$

(ii) The adjoint equation:

$$
\dot{\psi}=r \psi-\frac{\partial H}{\partial K}=r \psi-\beta h^{\alpha} K^{\beta-1}[v(1-\theta)+\psi s(1-v)]
$$

\footnotetext{
${ }^{4}$ The relevant sufficiency theorems are in Chapter 9 of Leonard and Long (1992).
} 
(iii) The transition equation:

$$
\dot{K}=\frac{\partial H}{\partial \psi}=s(1-v) h^{\alpha} K^{\beta}-g
$$

Let us define

$$
Z=Z(\psi, \theta) \equiv v(1-\theta)+\psi s(1-v)
$$

From (13) we can express $h$ as a function of $(K, \psi)$ and of the central government tax share parameter $\theta$ :

$$
h=\left[\alpha K^{\beta} Z\right]^{1 /(1-\alpha)} \text { if } Z \geq 0
$$

(and $h=0$ if $Z \leq 0$.) (We can expect that $\psi>0$ even in the case $\theta=1$, because the stock yields benefits to the local government: grabbing is not possible if the stock is zero.). Henceforth, we focus on the case $Z>0$.

Substituting (18) into (15) we get

$$
\dot{\psi}=r \psi-\beta(\alpha)^{\alpha /(1-\alpha)} Z^{1 /(1-\alpha)} K^{-\delta /(1-\alpha)} \equiv M(K, \psi, \theta)
$$

where

$$
\delta=1-\alpha-\beta .
$$

If $\delta=0$, the income function (11) is said to exhibit constant returns to scale. If $\delta>0$, we have decreasing returns to scale.

From (14) we can express $g$ as a function of $\psi$ and the effort cost parameter $\gamma$

$$
\begin{gathered}
g=\frac{1-\varepsilon-\psi}{\gamma} \text { if } \psi<1-\varepsilon \\
g=0 \text { if } \psi \leq 1-\varepsilon
\end{gathered}
$$

Substituting (20) and (18) into eq (16), we get

$$
\dot{K}=s(1-v) K^{\beta /(1-\alpha)}(\alpha)^{\alpha /(1-\alpha)} Z^{\alpha /(1-\alpha)}-\max \left(0, \frac{1-\varepsilon-\psi}{\gamma}\right) \equiv N(K, \psi, \theta)
$$

Remark: The polar case where $\theta=1$ deserves some mention. Note that if $\theta=1$ then the local government has zero tax revenue. Unlike the static case, this does not mean that the local government will choose $h=0$. If it were to set $h=0$ always, then it would be in effect facing a non-renewableresource exploitation problem, just like the classic Hotelling model of a mining firm. The shadow price would then be positive and would rise at the rate of interest (i.e., Hotelling Rule would apply). But then $Z$ would be positive, and the helping hand would be positive, by (18). 


\section{The Case of Constant Returns to Scale}

In this section, we analyze the case of constant returns to scale, i.e., $\delta=0$. Then equation (15) becomes

$$
\dot{\psi}=r \psi-\beta(\alpha)^{\alpha /(1-\alpha)} Z^{1 /(1-\alpha)} \equiv M(K, \psi, \theta)
$$

which is independent ${ }^{5}$ of $K$, and equation (21) becomes

$$
\dot{K}=s(1-v) K(\alpha)^{\alpha /(1-\alpha)} Z^{\alpha /(1-\alpha)}-\max \left(0, \frac{1-\varepsilon-\psi}{\gamma}\right) \equiv N(K, \psi, \theta)
$$

which is linear in $K$. Under this case, we consider two sub-cases: $\theta=1$ and $\theta<1$, and in particular, we search for steady states and their stability properties. (A steady state is a point $\left(K_{s s}, \psi_{s s}\right)$ such that $M\left(K_{s s}, \psi_{s s}, \theta\right)=0$ and $N\left(K_{s s}, \psi_{s s}, \theta\right)=0$.

\subsection{The sub-case $\theta=1$ under constant returns to scale}

At first sight, it might seem that if the central government's tax share is $\theta=1$, the local government might not have any incentive to extend the helping hand. Upon reflection, however, even though the local government's share of official tax revenue is zero, it knows that it can grab only as long as the capital stock remains positive. By extending the helping hand, it can reduce the rate of decline of the capital stock, and may even help maintain it at a steady-state level. So even if $\theta=1$, the local government's optimal behavior is like that of a manager of a fishery: it is in his interest to conserve the fish stock.

Our analysis will rely on the phase diagram method. For the present sub-case, please refer to Figure 1.We begin our analysis by characterizing the curve $\dot{\psi}=0$ in the space $(K, \psi)$. Let us look at the equation $M(K, \psi, \theta)=0$.

Since we are dealing with the case $\theta=1$, the equation $M(K, \psi, \theta)=0$ reduces to

$$
\frac{r \psi}{Q} K^{\delta /(1-\alpha)}=[s \psi(1-v)]^{1 /(1-\alpha)}
$$

where

$$
Q=\beta(\alpha)^{\alpha /(1-\alpha)}
$$

Now under constant returns to scale, $\delta=0$, equation (24) becomes

$$
\psi\left[\frac{r}{Q}-(s(1-v))^{1 /(1-\alpha)} \psi^{\alpha /(1-\alpha)}\right]=0
$$

\footnotetext{
${ }^{5}$ Even though $M$ is independent of case, there is no harm in writing $M(K, \psi, \theta)$.
} 
This equation has two solutions, which we denote as $\psi_{a}$ and $\psi_{b}$ :

$$
\begin{gathered}
\psi_{a}=0 \\
\psi_{b}=\left[\frac{r}{Q(s(1-v))^{1 /(1-\alpha)}}\right]^{(1-\alpha) / \alpha}>\psi_{a}
\end{gathered}
$$

Thus $\dot{\psi}=0$ along the horizontal line $\psi=0$ and along the horizontal line $\psi=\psi_{b}$. Note that $\psi_{b}$ can be greater than, or smaller than $1-\varepsilon$. Clearly, if $r$ is sufficiently small, then $\psi_{b}<1-\varepsilon$. Figure 1 depicts the case where $\psi_{b}<1-\varepsilon$.

Recall that with $\delta=0$ and $\theta=1$, the equation for $\dot{\psi}$ is

$$
\dot{\psi}=r \psi-Q[s \psi(1-v)]^{1 /(1-\alpha)}
$$

The right-hand side of (26) is strictly concave in $\psi$, and is equal to zero at $\psi=\psi_{a}=0$, and also at $\psi_{b}>\psi_{a}$. It follows that for $\psi<\psi_{a}$, we have $\dot{\psi}<0$. If $\psi \in\left(\psi_{a}, \psi_{b}\right)$, we have $\dot{\psi}>0$. If $\psi>\psi_{b}$, we have $\dot{\psi}<0$.

Now we characterize the curve $\dot{K}=0$ in the space $(K, \psi)$. Let us look at the equation $N(K, \psi, \theta)=0$. To have $\dot{K}=0$, we must have $g>0$ when $K>0$ and $\psi \geq 0$. Thus we infer that the curve $\dot{K}=0$ must lie below the line $\psi=1-\varepsilon$. The equation $N(K, \psi, \theta)=0$ can be written as

$$
\gamma(1-v)^{1 /(1-\alpha)}(\alpha s)^{\alpha /(1-\alpha)} K^{\beta /(1-\alpha)}=\frac{1-\psi-\varepsilon}{\psi^{\alpha /(1-\alpha)}}
$$

Thus, along this curve, $K$ is a function of $\psi$. Let us try to determine the shape of this curve. As $\psi \rightarrow(1-\varepsilon), K \rightarrow 0$, and as $\psi \rightarrow 0, K \rightarrow \infty$. We now show that the slope of the curve $\dot{K}=0$ is negative. Differentiating (27) with respect to $\psi$, we get

$$
\begin{gathered}
\gamma(1-v)^{1 /(1-\alpha)}(\alpha s)^{\alpha /(1-\alpha)}\left(\frac{\beta}{1-\alpha}\right) K^{-\delta /(1-\alpha)} \frac{d K}{d \psi}= \\
\frac{-\psi^{\alpha /(1-\alpha)}-(1-\psi-\varepsilon) \frac{\alpha}{1-\alpha} \psi^{(2 \alpha-1) /(1-\alpha)}}{\psi^{\alpha /(1-\alpha)}}
\end{gathered}
$$

which is negative for $\psi<(1-\varepsilon)$. Thus the curve $\dot{K}=0$ is downward sloping, and never cuts the horizontal axis.

It follows that the curve $\dot{K}=0$ intersects the curve $\dot{\psi}=0$ exactly once provided that $r$ is small enough to ensure that $\psi_{b}<(1-\varepsilon)$. This intersection is the steady-state point $\left(K_{s s}, \psi_{b}\right)$, where

$$
K_{s s}=\frac{1-\psi_{b}-\varepsilon}{\left[\gamma(1-v)^{1 /(1-\alpha)}(\alpha s)^{\alpha /(1-\alpha)}\right] \psi_{b}^{\alpha /(1-\alpha)}}
$$


From the phase diagram, we know that this steady state is stable in the saddlepoint sense. Thus the optimal policy is as follows.

If $K_{0}<K_{s s}$ then it is optimal to extend the helping hand to build up the stock $K$ until it reaches the steady state $K_{s s}$. Along such a path, the grabing activity may be zero over some initial time interval.

What happens if $K_{0}>K_{s s}$ ? At first sight, one might be tempted to think that the unstable branch of the saddlepoint, i.e., the path with $\psi(t)=\psi_{b}$ for ever, and with $K$ rising without bound, might be optimal. But upon reflection, this is not an optimal path, because along such a path, the pay-off to the local government is $(1-\delta) g-(1 / \gamma) g^{2}-h$ where $g$ is constant over time $\left(g=\left(1-\varepsilon-\psi_{b}\right) / \gamma\right)$ while $h$ is increasing over time. Clearly, it would be better to follow the stable branch of the saddlepoint, and set $g>\left(1-\varepsilon-\psi_{b}\right) / \gamma$ to ensure that $K$ falls from $K_{0}$ to $K_{s s}$, and once $K_{s s}$ is reached, choose $g=\left(1-\varepsilon-\psi_{b}\right) / \gamma$ so as to stay at the steady state. In fact, it can be verified that the path of capital accumulation with $\psi(t)=\psi_{b}$ for ever and $K(t)$ increasing at a constant rate fails to satisfy the transversality condition

$$
\lim _{t \rightarrow \infty} e^{-r t} \psi(t) K(t)=0 .
$$

Figure 1 corresponds to the case where $\psi_{b}<1-\varepsilon$ (which holds if the discount rate $r$ is low, i.e., if the local government is patient).If the rate of interest $r$ is high, i.e., the local government is impatient, then $\psi_{b}$ exceeds $1-\varepsilon$, and it follows that there will not exist any steady state. Then the optimal policy is to run the stock down to zero.

Proposition D1: Under constant returns to scale $(\delta=0)$, if the tax share of the central government is $100 \%(\theta=1)$, the optimal policy for the local government depends on the magnitude of the rate of discount $r$.

(a) If $r$ is sufficiently high to satisfy the following condition

$$
\left[\frac{r}{Q(s(1-v))^{1 /(1-\alpha)}}\right]^{(1-\alpha) / \alpha} \geq 1-\varepsilon
$$

then there does not exist any interior steady state. The optimal policy for the local government is to let the capital stock fall to zero. Along such path, the grabing activity $g(t)$ is positive and decreasing over time (in much the same way as the extraction of an exhaustible resource), while the hepling activity h(t) is always positive, until the stock is exhausted. If the condition (28) holds with equality, then the point $(K, \psi)=(0,1-\varepsilon)$ is a steady state, and the capital stock tends to zero as time tends to infinity.

(b) If $r$ is low, so that inequality (28) is reversed, then there is an interior steady state $\left(K_{s s}, \psi_{b}\right)>$ $(0,0)$, with the saddlepoint property. If the initial stock $K_{0}$ is below the steady state level $K_{s s}$, it is optimal to extend the helping hand to build up the stock $K$ until it reaches the steady state $K_{s s}$. Along 
such a path, the grabbing activity may be zero over some initial time interval. If $K_{0}>K_{s s}$, then grabbing dominates helping, and the stock will fall toward $K_{s s}$.

\subsection{The sub-case $\theta<1$ under constant returns to scale}

In this sub-case, the local government has positive tax revenue as well as extortion revenue. The phase diagrams are Figures 2 and 3. The curve $\dot{\psi}=0$ is given by

$$
\left(\frac{r}{Q}\right)^{1-\alpha} K^{\delta}=\frac{Z(\psi, \theta)}{\psi^{1-\alpha}}
$$

where

$$
Z(\psi, \theta)=v(1-\theta)+\psi s(1-v)
$$

Under constant returns to scale, $\delta=0$, equation (29) becomes

$$
\frac{r}{Q} \psi-[v(1-\theta)+\psi s(1-v)]^{1 /(1-\alpha)}=0
$$

Since the left-hand side of equation (30) is a concave function of $\psi$, this equation has at most two real roots, which we denote by $\psi_{1}$ and $\psi_{2} \geq \psi_{1}$. For example, suppose $\alpha=1 / 2$, then

$$
\frac{r}{Q} \psi-(v(1-\theta)+\psi s(1-v))^{2}=0
$$

i.e.,

$$
(1-v)^{2} s^{2} \psi^{2}+\left[2 s v(1-v)(1-\theta)-\frac{r}{Q}\right] \psi+v^{2}(1-\theta)^{2}=0
$$

This equation has two roots (both real, or both complex):

$$
\begin{aligned}
& \psi_{1}=\frac{\frac{r}{Q}-2 s v(1-v)(1-\theta)-\sqrt{\Delta}}{2(1-v)^{2} s^{2}} \\
& \psi_{2}=\frac{\frac{r}{Q}-2 s v(1-v)(1-\theta)+\sqrt{\Delta}}{2(1-v)^{2} s^{2}}
\end{aligned}
$$

where

$$
\Delta=\frac{r}{Q^{2}}[r-4 Q s v(1-v)(1-\theta)]
$$

Consider the following Assumption:

Assumption 1: $r-4 Q s v(1-v)(1-\theta) \geq 0$.

If Assumption 1 is satisfied, we have $\Delta \geq 0$, thus we have two real roots. Note that both roots are positive. (This is because the product of the roots equals $v^{2}(1-\theta)^{2}$ and the sum of the roots equals

$$
\psi_{1}+\psi_{2}=\frac{\frac{r}{Q}-2 s v(1-v)(1-\theta)}{2(1-v)^{2} s^{2}}
$$


which is positive, given Assumption 1.)

Recall that with $\delta=0$ and $\theta<1$, the equation for $\dot{\psi}$ is

$$
\dot{\psi}=M(K, \psi, \theta)=r \psi-Q[v(1-\theta)+s \psi(1-v)]^{1 /(1-\alpha)}
$$

The right-hand side of (34) is concave in $\psi$. It follows that for $\psi<\psi_{1}$, we have $\dot{\psi}<0$. If $\psi \in\left(\psi_{1}, \psi_{2}\right)$, we have $\dot{\psi}>0$. If $\psi>\psi_{2}$, we have $\dot{\psi}<0$.

In the space $(K, \psi)$, the line $\psi=\psi_{1}$ and the line $\psi=\psi_{2}$ divide the first quadrant $\{(K, \psi): K \geq 0$ and $\psi \geq 0\}$ into three regions. In the region $A$, defined as the set of points $(K, \psi)$ with $K \geq 0$ and $\psi>\psi_{2}$, we have $M(K, \psi, \theta)<0$ hence $\dot{\psi}<0$. In the region $C$, defined as the set of points $(K, \psi)$ with $K \geq 0$ and $\psi<\psi_{1}$, we also have $M(K, \psi, \theta)<0$ hence $\dot{\psi}<0$. In the region $B$ defined as the set points $(K, \psi)$ with $K \geq 0$ and $\psi \in\left(\psi_{1}, \psi_{2}\right)$ (between the line $\psi=\psi_{1}$ and the line $\psi=\psi_{2}$ ), we have $\dot{\psi}>0$. In other words

$$
\begin{gathered}
M(K, \psi, \theta)>0 \text { in region } B \\
M(K, \psi, \theta)<0 \text { in regions } A \text { and } C .
\end{gathered}
$$

Turning now to the curve $\dot{K}=0$ i.e., $N(K, \psi, \theta)=0$, we note that, for $\psi<1-\varepsilon$, this equation can be written as

$$
K^{\beta /(1-\alpha)}=\frac{1-\varepsilon-\psi}{\gamma s(1-v)(\alpha)^{\alpha /(1-\alpha)}[v(1-\theta)+\psi s(1-v)]^{\alpha /(1-\alpha)}}
$$

This curve has a negative slope in the space $(K, \psi)$. Along this curve, as $\psi \rightarrow 1-\varepsilon$, we have $K \rightarrow 0$. The curve cuts the horizontal axis at a finite value of $K$. To see this, observe that as $\psi \rightarrow 0, K$ tends to $\widetilde{K}$ where

$$
\widetilde{K}=\left[\frac{1-\varepsilon}{\gamma s(1-v)(\alpha)^{\alpha /(1-\alpha)}(v(1-\theta))^{\alpha /(1-\alpha)}}\right]^{(1-\alpha) / \beta}
$$

Along the curve (35), we have $N(K, \psi, \theta)=0$ hence $\dot{K}=0$. Above this curve, we have $\dot{K}>0$ because

$$
\frac{\partial N}{\partial \psi}>0
$$

Below it, $\dot{K}<0$.

We now determine the steady-state points. Please refer to Figures 2 and 3. In Figure 2, $r$ is small enough so that $\psi_{2}<1-\varepsilon$. Corresponding to $\psi_{2}$ and $\psi_{1}$, we have from (35) two steady state levels for the capital stock:

$$
K_{2}=\left[\frac{1-\varepsilon-\psi_{2}}{\gamma s(1-v)(\alpha)^{\alpha /(1-\alpha)}\left[v(1-\theta)+\psi_{2} s(1-v)\right]^{\alpha /(1-\alpha)}}\right]^{(1-\alpha) / \beta}
$$




$$
K_{1}=\left[\frac{1-\varepsilon-\psi_{1}}{\gamma s(1-v)(\alpha)^{\alpha /(1-\alpha)}\left[v(1-\theta)+\psi_{1} s(1-v)\right]^{\alpha /(1-\alpha)}}\right]^{(1-\alpha) / \beta}>K_{2}
$$

It is easy to see that the steady-state point $\left(K_{2}, \psi_{2}\right)$ is stable in the saddlepoint sense. The other steady state point, $\left(K_{1}, \psi_{1}\right)$, is unstable. This is confirmed by linearization of the dynamic system around a steady state.

In Figure 3, $r$ is so high that $\psi_{2}>1-\varepsilon$, and thus there is only one steady state point.

Proposition D2: Assume $\theta<1$, and constant returns to scale $(\delta=0)$. If $r$ is small enough so that $\psi_{2}<1-\varepsilon$, then there exists two interior steady states. The one with a smaller steady-state stock (and a higher shadow price) is stable in the saddlepoint sense. The other steady state is unstable. If $r$ is large enough so that $\psi_{2}>1-\varepsilon$, then there exists only one interior steady state, and it is completely unstable.

Remark: The above analysis tells us the following things about the optimal policy:

(a) if there are two steady states (as in Figure 2), and if $K_{0}<K_{1}$, we simply take the stable branch of the saddlepoint and approach the steady state point $\left(K_{2}, \psi_{2}\right)$.

(b) if there is only one steady state (as in Figure 3), and if $K_{0}<K_{1}$, we run the stock down to zero (appoaching the point $(K, \psi)=(0,1-\varepsilon)$.

(c) if $K_{0}$ happens to be equal to $K_{1}$, then the optimal policy is to set $\psi_{0}=\psi_{1}$ and thus the system will remain at the unstable steady state point $\left(K_{1}, \psi_{1}\right)$ for ever.

What is not obvious, however, is what one should do if $K_{0}$ is greater than $K_{1}$ ? There is no path that leads to an interior steady state, starting at $K_{0}>K_{1}$. One is tempted to conjecture that, for any $K_{0}>K_{1}$, the optimal policy is to choose $\psi_{0}=\psi_{1}$ so that $\psi(t)=\psi_{1}$ for ever, and let the capital stock increase without bound. Such a path would be optimal if the following transversality condition is satisfied

$$
\lim _{t \rightarrow \infty} e^{-r t} \psi(t) K(t)=0
$$

Let us check to see if condition (37) is satisfied along the path of unbounded growth of the capital stock, with $\psi(t)=\psi_{1}$ for ever. Let us take the case where $\alpha=\beta=1 / 2$. Under assumption 1 , we have two real roots $\psi_{2}$ and $\psi_{1}$.Using (31), we get

$$
\psi_{1}=\frac{2 r-s v(1-v)(1-\theta)-\sqrt{4 r(r-s v(1-v)(1-\theta))}}{(1-v)^{2} s^{2}}
$$

Let

$$
b \equiv s v(1-v)(1-\theta)
$$


then

$$
(1-v)^{2} s^{2} \psi_{1}=2 r-b-\sqrt{4 r(r-b)}>2 r-b-\sqrt{(2 r-b)^{2}}=0
$$

thus $\psi_{1}>0$.

Next, from (13),

$$
\frac{\partial H}{\partial h}=\frac{1}{2} h^{-1 / 2} K^{1 / 2}[v(1-\theta)+\psi s(1-v)]-1=0
$$

Thus

$$
h^{1 / 2}=\frac{1}{2} K^{1 / 2}[v(1-\theta)+\psi s(1-v)]
$$

On the other hand, from (16)

$$
\dot{K}=\frac{\partial H}{\partial \psi}=s(1-v) h^{1 / 2} K^{1 / 2}-\frac{1-\psi-\varepsilon}{\gamma}
$$

Substituting (40) into (41), we get

$$
\dot{K}=\frac{1}{2} s(1-v) K[v(1-\theta)+\psi s(1-v)]-\frac{1-\psi-\varepsilon}{\gamma}
$$

Setting $\psi=\psi_{1}$ in (42), we see that $\dot{K}=0$ if and only if $K=K_{1}$, where

$$
K_{1}=\frac{2\left(1-\psi_{1}-\varepsilon\right)}{\gamma s(1-v)\left[v(1-\theta)+\psi_{1} s(1-v)\right]}
$$

Thus, given that $K_{0}>K_{1}$, if we set $\psi(t)=\psi_{1}$ for all $t$, then $\dot{K}>0$ for all $K(t)>K_{1}$, and eventually

$$
\frac{\dot{K}}{K} \rightarrow \frac{1}{2} s(1-v)\left[v(1-\theta)+\psi_{1} s(1-v)\right] \equiv \sigma
$$

The transversality condition (37) is satisfied iff $-r+\sigma<0$, i.e. iff

$$
(1-v)^{2} s^{2} \psi_{1}<2 r-s v(1-v)(1-\theta)=2 r-b
$$

This condition is satisfied, in view of (39).

Thus we have established the following proposition:

Proposition D3: Let $\left(K_{1}, \psi_{1}\right)$ denote the unstable steady state. Then, if $K_{0}>K_{1}$, the optimal policy is to set $\psi(t)=\psi_{1}$ and let $K(t)$ grow without bound. This path satisfies all the necessary conditions, and the transversality condition, and is therefore optimal ${ }^{6}$. Along the optimal path, grabbing is a constant, and local government tax revenue, net of expenditure on helping, is a constant proportion of income, which grows without bound.

\footnotetext{
${ }^{6}$ Sufficiency is ensured by the concavity of the Hamiltonian with respect to the variables $(K, h, g)$
} 


\section{Implications: threshold levels of corruption and tax share}

The analysis in the preceeding section indicates that, for any intitial level of capital stock, $K_{0}$, there is a threshold level of corruption and a threshold level of central government tax share, below which the economy will grow without bound, and above which the economy will stagnate. As we have seen, if $K_{0}>K_{1}$, the economy will grow without bound, and corruption (as measured by the ratio $g / Y$, i.e., the proportion of income that is grabbed by government officials) will fall steadily. This critical level $K_{1}$ is a function of the parameters $\varepsilon, \gamma$ and $\theta$. It is not difficult to show that $K_{1}$ is increasing in $\theta$ and decreasing in $\varepsilon$ and $\gamma$. To prove this, consider equations (38) and (43). From equation (38), we see that $\psi_{1}$ is dependent on $\theta$ and independent of $\varepsilon$ and $\gamma$. Differentiating (38), we get

$$
(1-v)^{2} s^{2} \frac{d \psi_{1}}{d \theta}=s v(1-v)\left[1-\frac{1}{\sqrt{r(r-s v(1-v)(1-\theta))}}\right]<0
$$

where the inequality follows from $r<1$.

Now, differentiating (43) with respect to $\theta$, holding constant the parameters $\gamma$ and $\varepsilon$ :

$$
\frac{\partial K_{1}}{\partial \theta}=\frac{-[v(1-\theta)+(1-\varepsilon) s(1-v)] \frac{d \psi_{1}}{d \theta}+v\left(1-\psi_{1}-\varepsilon\right)}{\frac{1}{2} \gamma s(1-v)\left[v(1-\theta)+\psi_{1} s(1-v)\right]^{2}}>0
$$

Similarly, differentiating (43) with respect to $\gamma$, holding constant the parameters $\theta$ and $\varepsilon$ :

$$
\frac{\partial K_{1}}{\partial \gamma}=\frac{-2\left(1-\psi_{1}-\varepsilon\right) \gamma^{-2}}{s(1-v)\left[v(1-\theta)+\psi_{1} s(1-v)\right]}<0
$$

and, differentiating (43) with respect to $\varepsilon$, holding constant the parameters $\theta$ and $\gamma$ :

$$
\frac{\partial K_{1}}{\partial \gamma}=\frac{-2\left(1-\psi_{1}-\varepsilon\right)}{\gamma s(1-v)\left[v(1-\theta)+\psi_{1} s(1-v)\right]}<0
$$

It follows that, given the initial capital stock level $K_{0}$, a change in the parameter $\theta$ can have qualitatively significant effects on the course of development of the economy. Suppose that initially $\theta$ is sufficiently low, so that $K_{1}(\theta, \varepsilon, \gamma)<K_{0}$. Then the local economy is due to embark on an expansion path with ever-rising capital and income. But if there is a policy shift by the central government that results in a higher $\theta$ (say from $\theta_{L}$ to $\theta_{H}>\theta_{L}$ ) such that $K_{1}\left(\theta_{H}, \varepsilon, \gamma\right)>K_{0}$, then the local economy will stagnate: the capital stock falls and converges to a low-level steady state.

Similarly, the parameters $\varepsilon$ and $\gamma$ indicate how difficult it is to carry out grabbing activities. An increase in $\varepsilon$ or $\gamma$ represents an increase in the level of transparency of governance at the local government level. An increase in transparency will reduce $K_{1}$ below $K_{0}$ thus enabling the economy to achieve perpetual growth. 
Proposition D4: (i) Given any initial capital stock, there exists a corresponding threshold level of central government tax share, below which the economy will achieve perpetual growth, and above which the economy will stagnate.

(ii) Given any initial capital stock, there exists a corresponding threshold level of transparency of governance, above which the economy will achieve perpetual growth, and below which the economy will stagnate.

\section{The Case of Decreasing Returns to Scale}

We now consider the case $\delta>0$

\subsection{The sub-case $\theta=1$ under decreasing returns to scale}

We begin our analysis of this sub-case by characterizing the curve $\dot{\psi}=0$ in the space $(K, \psi)$. Consider Figure 4. Let us look at the equation $M(K, \psi, \theta)=0$. Since we are dealing with the case $\theta=1$, that equation is reduced to

$$
\frac{r \psi}{Q} K^{\delta /(1-\alpha)}=[s \psi(1-v)]^{1 /(1-\alpha)}
$$

where

$$
Q=\beta(\alpha)^{\alpha /(1-\alpha)}
$$

Since $\delta>0$, the curve $\dot{\psi}=0$ must satisfy the equation

$$
\left(\frac{r}{Q}\right)^{1-\alpha} K^{\delta}=\psi^{\alpha}(s(1-v))
$$

Thus the curve $\dot{\psi}=0$ is upward-sloping in the space $(K, \psi)$. Since

$$
\frac{\partial M(K, \psi, \theta)}{\partial K}>0
$$

we infer that $\dot{\psi}>0$ to the right of the curve $\dot{\psi}=0$ and $\dot{\psi}<0$ to its left.

Now we try to characterize the curve $\dot{K}=0$ in the space $(K, \psi)$. Let us look at the equation $N(K, \psi, \theta)=0$. To have $\dot{K}=0$, we must have $g>0$ when $K>0$ and $\psi \geq 0$. Thus we infer that the curve $\dot{K}=0$ must lie below the line $\psi=1-\varepsilon$. The equation $N(K, \psi, \theta)=0$ can be written as

$$
\gamma(1-v)^{1 /(1-\alpha)}(\alpha s)^{\alpha /(1-\alpha)} K^{\beta /(1-\alpha)}=\frac{1-\psi-\varepsilon}{\psi^{\alpha /(1-\alpha)}}
$$


Thus, along this curve, $K$ is a function of $\psi$. Let us try to determine the shape of this curve. As $\psi \rightarrow(1-\varepsilon), K \rightarrow 0$, and as $\psi \rightarrow 0, K \rightarrow \infty$. We now show that the curve $K=0$ has a negative slope. Differentiating (45) with respect to $\psi$, we get

$$
\begin{gathered}
\gamma(1-v)^{1 /(1-\alpha)}(\alpha s)^{\alpha /(1-\alpha)}\left(\frac{\beta}{1-\alpha}\right) K^{-\delta /(1-\alpha)} \frac{d K}{d \psi}= \\
\frac{-\psi^{\alpha /(1-\alpha)}-(1-\psi-\varepsilon) \frac{\alpha}{1-\alpha} \psi^{(2 \alpha-1) /(1-\alpha)}}{\psi^{\alpha /(1-\alpha)}}
\end{gathered}
$$

which is negative for $\psi<(1-\varepsilon)$. Thus we can infer from (45) and (46) that the curve $\dot{K}=0$ is downward sloping, and never cuts the horizontal axis.

It follows that the curve $\dot{K}=0$ intersects the curve $\dot{\psi}=0$ exactly once given that $\delta>0$. This intersection is the steady-state point $\left(K_{s s}, \psi_{s s}\right)$. From the phase diagram (Figure 4), we know that this steady state is stable in the saddlepoint sense.

Proposition D5: Assume $\theta=1$. Under decreasing returns to scale, regardless of the magnitude of the interest rate, there exists a unique interior steady state point $\left(K_{s s}, \psi_{s s}\right)$. This unique steady state has the saddlepoint property. Starting from any $K_{0}>0$, the optimal path is the stablebranch of the saddlepoint, leading to the interior steady state. For $K_{0}<K_{s s}$, grabbing activities begin at a low level (possibly zero), and intensify as the capital stock grows toward $K_{s s}$. For $K_{0}>K_{s s}$, grabbing activities begin at a high level, and diminish as the capital stock falls towards $K_{s s}$.

Remark: Compare Figure 4 with Figure 1. The qualitative properties of the respective optimal paths are very similar. This is not surprising, because in both situations the tax share of the central government is 100 per cent.

\subsection{The sub-case $\theta<1$ under decreasing returns to scale}

Figure 5 is the phase diagram for this sub-case. Equation (29) gives us the curve $\dot{\psi}=0$, and along this curve, $K$ can be expressed as a function of $\psi$. Differentiating both sides with respect to $\psi$, we get

$$
\left(\frac{r}{Q}\right)^{1-\alpha} \delta K^{\delta-1} \frac{d K}{d \psi}=\frac{\psi^{-\alpha}}{\psi^{2 /(1-\alpha)}}[s \alpha(1-v) \psi-v(1-\alpha)(1-v)]
$$

Define

$$
\widehat{\psi}=\frac{v(1-\alpha)(1-v)}{s \alpha(1-v)}
$$

Along the curve $\dot{\psi}=0$, we have $K$ as a decreasing function of $\psi$ for $\psi \in(0, \widehat{\psi})$ and $K$ as an increasing function of $\psi$ for $\psi>\widehat{\psi}$. In the space $(K, \psi)$, the curve $\dot{\psi}=0$ has the shape of the letter $C$. To the 
right of this curve, we have $\dot{\psi}>0$, because $\partial M / \partial K>0$. At the turning point of the letter $C$-shaped curve, we have

$$
\begin{gathered}
\psi=\widehat{\psi}=\frac{v(1-\alpha)(1-v)}{s \alpha(1-v)} \\
K=\widehat{K}=\left[\frac{Z(\widehat{\psi}, \theta)}{\widehat{\psi}^{1-\alpha}}\left(\frac{Q}{r}\right)^{1-\alpha}\right]^{1 / \delta}
\end{gathered}
$$

Now consider the curve $\dot{K}=0$. We note that, for $\psi<1-\varepsilon$, this equation can be written as

$$
K^{\beta /(1-\alpha)}=\frac{1-\varepsilon-\psi}{\gamma s(1-v)(\alpha)^{\alpha /(1-\alpha)}[v(1-\theta)+\psi s(1-v)]^{\alpha /(1-\alpha)}}
$$

This curve has a negative slope in the space $(K, \psi)$. Along this curve, as $\psi \rightarrow 1-\varepsilon$, we have $K \rightarrow 0$. The curve cuts the horizontal axis at a finite value of $K$. To see this, observe that as $\psi \rightarrow 0, K$ tends to $\widetilde{K}$ where

$$
\widetilde{K}=\left[\frac{1-\varepsilon}{\gamma s(1-v)(\alpha)^{\alpha /(1-\alpha)}(v(1-\theta))^{\alpha /(1-\alpha)}}\right]^{(1-\alpha) / \beta}
$$

Along the curve (48), we have $N(K, \psi, \theta)=0$ hence $\dot{K}=0$. Above this curve, we have $\dot{K}>0$ because

$$
\frac{\partial N}{\partial \psi}>0
$$

Below it, $\dot{K}<0$.

We now determine the steady-state points. Since the curve $\dot{\psi}=0$ has the $C$ shape, and the curve $\dot{K}=0$ is downward sloping, there is the possibility of several intersections.

Proposition 6: Assume $\theta<1$ and $\delta>0$ (decreasing returns to scale). There may exist several steady states. The one with the smallest capital stock is stable in the saddlepoint sense. It is also possible that there does not exist any interior steady state (for example, if $\widehat{K}<\widetilde{K}$ ). In the latter case, the optimal path is to run down the stock to zero in finite time.

Remark: In Figure 5, we show two steady-state points, $\left(K_{1}, \psi_{1}\right)$ and $\left(K_{2}, \psi_{2}\right)$. The point $\left(K_{2}, \psi_{2}\right)$ is stable in the saddlepoint sense. For all $K_{0} \in\left(0, K_{1}\right)$, the optimal policy is to follow the stable branch of the saddlepoint and approach $\left(K_{2}, \psi_{2}\right)$ asymptotically. If $K_{0}=K_{1}$, it is optimal to stay at $K_{1}$ for ever. If $K_{0}>K_{1}$ it seems that the optimal policy is to let $K$ grow for ever (in much the same way as the constant path $\psi(t)=\psi_{1}$ in Figure 2.) 


\section{Local stability analysis by linearization}

In the preceding section, we relied on the phase-diagram approach in our analysis of stability. We now compliment that analysis by the method of linearization of the dynamic system around an interior steady state. This method also permits comparative dynamics (across steady states, as parameters of the system change).

\subsection{Local stability analysis}

We have the dynamic system

$$
\begin{gathered}
\dot{K}=\frac{\partial H}{\partial \psi} \equiv N(K, \psi, \theta, \gamma) \\
\dot{\psi}=r \psi-\frac{\partial H}{\partial K} \equiv M(K, \psi, \theta)
\end{gathered}
$$

Linearization around a steady state yields

$$
\left[\begin{array}{c}
\dot{K} \\
\dot{\psi}
\end{array}\right]=\left[\begin{array}{cc}
H_{\psi K} & H_{\psi \psi} \\
-H_{K K} & r-H_{K \psi}
\end{array}\right]\left[\begin{array}{c}
K-K_{s s} \\
\psi-\psi_{s s}
\end{array}\right]
$$

This system has two chracteristic roots, $\lambda_{1}$ and $\lambda_{2}$. The sum of the roots is

$$
\lambda_{1}+\lambda_{2}=r>0
$$

and the product is

$$
\lambda_{1} \lambda_{2}=-\left(H_{K \psi}\right)^{2}+r H_{K \psi}+H_{\psi \psi} H_{K K}=H_{K \psi}\left(r-H_{K \psi}\right)+H_{\psi \psi} H_{K K}
$$

If the product $\lambda_{1} \lambda_{2}$ is negative, we have saddlepoint stability (i.e., one root has negative real part, and the other has positive real part). If the product is positive, the steady state is unstable. Now it is clear that $H_{\psi \psi}=N_{\psi}>0$ and $H_{K K}=M_{K}=0$. From (19) we have

$$
H_{K \psi}>0
$$

Let us apply this analysis to the steady-state points $\left(K_{1}, \psi_{1}\right)$ and $\left(K_{2}, \psi_{2}\right)$ of the section on constant returns to scale, with $\theta<1$. At the steady state $\left(K_{2}, \psi_{2}\right)$ we have $r-H_{K \psi}<0$, hence $\lambda_{1} \lambda_{2}<0$ thus it is stable in the saddlepoint sense. At the steady state $\left(K_{1}, \psi_{1}\right)$ we have $r-H_{K \psi}>0$, hence $\lambda_{1} \lambda_{2}>0$ thus it is unstable. 


\subsection{Comparative dynamics}

We now study how an increase in the parameter $\theta$ affects the position of the stable steady state.

At the steady state, we have

$$
\begin{gathered}
N\left(K_{s s}, \psi_{s s}, \theta, \gamma\right)=0 \\
M\left(K_{s s}, \psi_{s s}, \theta\right)=0
\end{gathered}
$$

To see how the steady state changes with an increase in $\theta$, we differentiate the system totally:

$$
\begin{gathered}
N_{K} d K_{s s}+N_{\psi} d \psi_{s s}+N_{\theta} d \theta=0 \\
M_{K} d K_{s s}+M_{\psi} d \psi_{s s}+M_{\theta} d \theta=0
\end{gathered}
$$

In matrix notation

$$
\left[\begin{array}{ll}
N_{K} & N_{\psi} \\
M_{K} & M_{\psi}
\end{array}\right]\left[\begin{array}{c}
\frac{d K_{s s}}{d \theta} \\
\frac{d \psi_{s s}}{d \theta}
\end{array}\right]=-\left[\begin{array}{c}
N_{\theta} \\
M_{\theta}
\end{array}\right]
$$

Using Cramer's rule, we get

$$
\frac{d K_{s s}}{d \theta}=\frac{1}{\Delta}\left[M_{\theta} N_{K}-N_{\theta} M_{\psi}\right]
$$

where, at the steady state,

$$
\Delta=N_{K} M_{\psi}-M_{K} N_{\psi}=\lambda_{1} \lambda_{2}<0
$$

Let us apply this to the (saddlepoint stable) steady-state point $\left(K_{2}, \psi_{2}\right)$ of the section on constant returns to scale, with $\theta<1$. The numerator of the right-hand side of (49) can be computed as follows.

$$
\begin{gathered}
M_{\theta}=Z v>0 \\
N_{K}=\frac{(1-v)^{2} K}{2}+\frac{1}{\gamma}>0 \\
N_{\theta}=-\frac{(1-v) K v}{2}<0 \\
M_{\psi}=r-(1-v) Z
\end{gathered}
$$

Thus

$$
M_{\theta} N_{K}-N_{\theta} M_{\psi}=\frac{v Z}{\gamma}+\frac{r(1-v) K v}{2}>0
$$

This establishes proposition D7 below.

Proposition D7: Concerning the steady state that is stable in the saddlepoint sense, an increase in $\theta$ (the tax share of the central government) will lead to a fall in the steady-state capital stock, and a rise in the steady-state shadow price $\psi$. 


\section{Concluding Remarks}

We have shown that a corrupt local government may have long term interest in the health of the local economy. Thus its activities consist of helping as well as grabbing. Depending on the initial level of the capital stock being higher or lower than a certain threshold level, the outcome for the local economy may be perpetual growth at a positive rate (as in the $A K$ model in the endogenous growth literature), or stagnation (a low level poverty trap). An important property of our results is that the threshold level of capital is a decreasing function of the central government tax share. Thus, the greater is the central government tax share, the more likely is the stagnation outcome. Another way of putting this is: given an initial capital stock $K_{0}$, there is a threshold level of central government tax share, beyond which the economy will become stagnated, and below which perpetual growth will be achieved.

We also showed that the threshold level of capital is a decreasing function of the transparency of local governance (i.e., a decreasing function of the parameters $\varepsilon$ and $\gamma$ that reflect the difficulty of hiding extortion). Thus any increase in transparency will increase the likelihood that the economy can take off.

The model can be extended in several directions. First, the central government's choice of the tax rate and of its revenue share could be explicitly modelled. This would lead to a study of interesting interactions between the central government and the local government. Second, one could suppose that capital is mobile across several local regions, and thus there would be competition among various local governments. These extensions would involve an analysis of differential games ${ }^{7}$, possibly with a hierarchical structures. Finally, political uncertainty about the possibility of losing office can be added to the model, along the lines of Long (1975) and Konrad et al. (1994).

\footnotetext{
${ }^{7}$ For some examples of differential games in economics, see Benchekroun and Long $(1998,2002)$. For a comprehensive treatment of differential games, including those with a hierarchical structures, see Docker et al. (2000).
} 


\section{References}

[1] Acemoglu, Daron, and Thierry Verdier, 2002, Property rights, corruption, and the allocation of talent: a general equilibrium appraoch, Economic Journal 108(405), 1381-1403.

[2] Ades, Alberto, and Rafael Di Tella, 2002, Rents, Competition, Corruption, American Economic Review 89(4), 982-93.

[3] Bardhan, Pranab, 1997, Corruption and Development: A Reviee of Issues, Journal of Economic Literature 35, 1320-46.

[4] Basu, Kaushik, Sudipto Bhattacharya, and Ajit Mishra, 1992, Notes on Bribery and the Control of Corruption, Journal of Public Economics 48, 349-59.

[5] Benchekroun, Hassan, and Ngo Van Long, 1998, Efficiency-inducing Taxation for Polluting Oligopolists, Journal of Public Economics 70, 325-42.

[6] Benchekroun, Hassan, and Ngo Van Long, 2002, Transboundary Fishery: A differential game model, Economica 69, 207-21.

[7] Brennan, Geoffrey and James Buchanan, 1977, Towards a tax constitution for Leviathan, Journal of Public Economics 8, 255-73.

[8] Brennan, Geoffrey and James Buchanan, 1980, The Power to Tax: Analytical Foundations of a Fiscal Constitution, Cambridge University Press, Cambridge, U.K.

[9] Chen Kang, Choice of the form of corruption: a perspective on fiscal centralization in China, European Journal of Political Economy, to appear.

[10] Dockner, E., S. Jorgensen, Ngo Van Long, and Gerhard Sorger, 2000, Differential Games in Economics and Management Science, Cambridge University Press, Cambridge, U.K.

[11] Frye, T. and A, Schleifer, 1997, The Invisible hand and the grabbing hand, American Economic Review, Papers and Proceedings, 87, 354-8.

[12] Keen, M. and C. Kotsogiannis, Leviathan and capital tax competition in federations, Journal of Public Economic Theory, 2003, Vol 5, 177-199.

[13] Kemp, Murray C., Ngo Van Long, and Koji Shimomura, 1993, Cyclical and non-cyclical redistributive taxation, International Economic Review, 34, 415-430.

[14] Konrad, Kai A., Trond E. Olsen, and Ronnie Schob, 1994, Resource extraction under the threat of possible expropriation: the role of Swiss bank accounts, Journal of Environmental Economics and Management, 26, 149-62.

[15] Leonard, Daniel, and Ngo Van Long, 1992, Optimal Control Theory and Static Optimization in Economics, Cambridge University Press, Cambridge, U.K.

[16] Long, Ngo Van, 1975, Resource Extraction under uncertainty about possible nationalization, Journal of Economic Theory 10, 42-53.

[17] Long, Ngo Van, and Koji Shimomura, 2002, Redistributive taxation in closed and open economies, in Alan Woodland, ed., Economic Theory and International Trade, Edward Elgar, London, 104-113. 
[18] Mauro, Paulo, 1995, Corruption and Growth, Quarterly Journal of Economics 110(3), 681-712.

[19] Ni, Shawn, and Pham Hoang Van, 2003, High corruption income as a source of distortion and stagnation: some evidence from Ming and Qing China, Typescript, University of Missouri.

[20] Olson, M., 1993, Dictatorship, democracy, and development, American Political Science Review $87,567-576$

[21] Olson, M., 2000, Power and Prosperity: Outgrowing Communist and Capitalist Dictatorships, Basic Book, New York.

[22] Rees, Ray, John Komlos, Ngo Van Long and U. Woitek, 2003, Optimal Food Allocation in a Slave Economy, Journal of Population Economics 16, 21-36.

[23] Schleifer, Andre, and Robert Vishny, 1993, Corruption, Quarterly Journal of Economics 108(3), 599-617.

[24] Tornell, Aaron and Andres Velasco, 1992, The tragedy of the common and economic growth: why does capital flow from poor to rich countries, Journal of Political Economy 100(6), 1208-31.

[25] Tornell, Aaron and Philip R. Lane, 1999, The voracity effect, American Economic Review 89(1) $22-46$. 
FIGURE 1

$\theta=1, \delta=0$

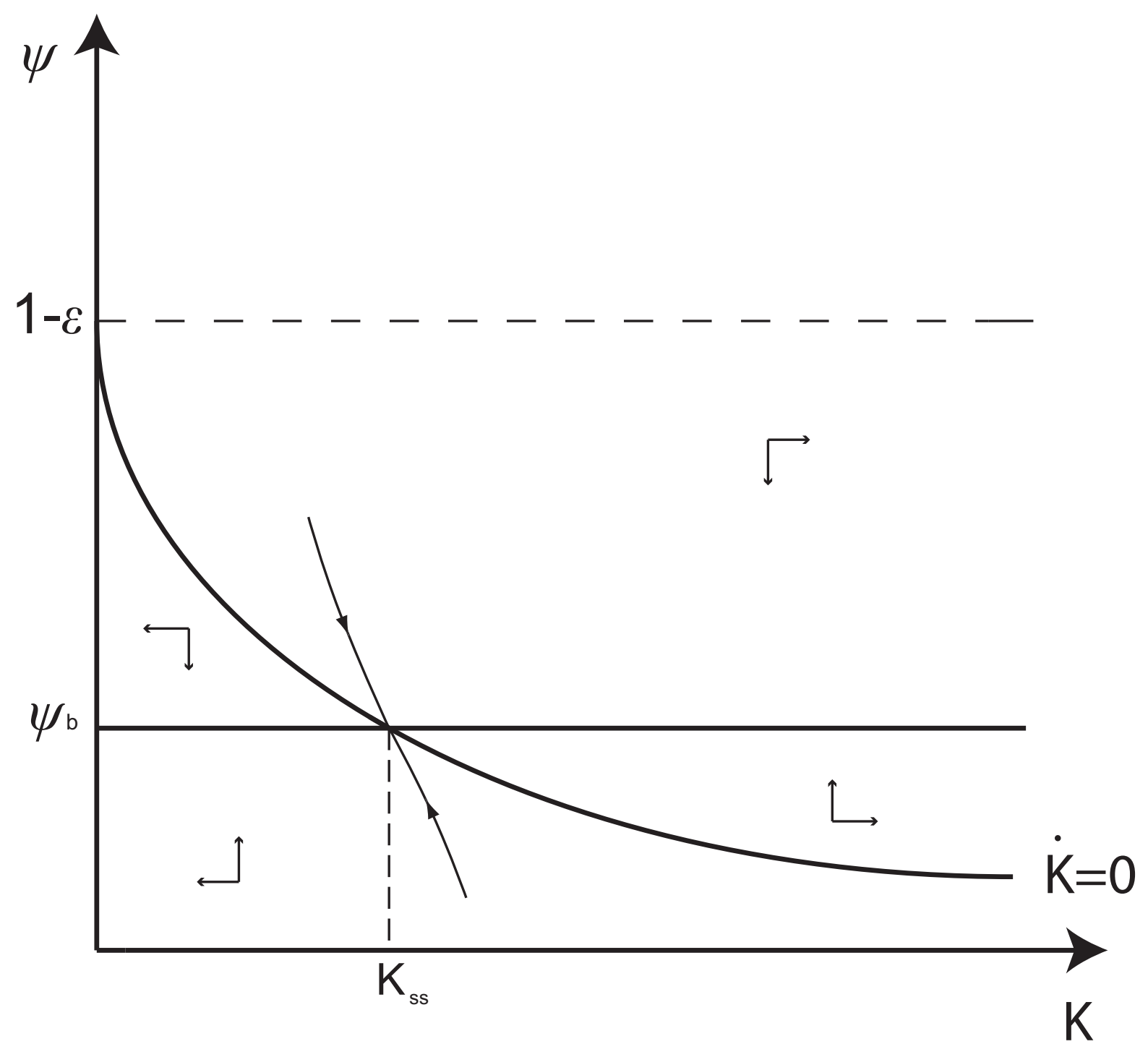


FIGURE 2

$\theta<1, \quad \delta=0, \quad \psi_{2}<1-\varepsilon$

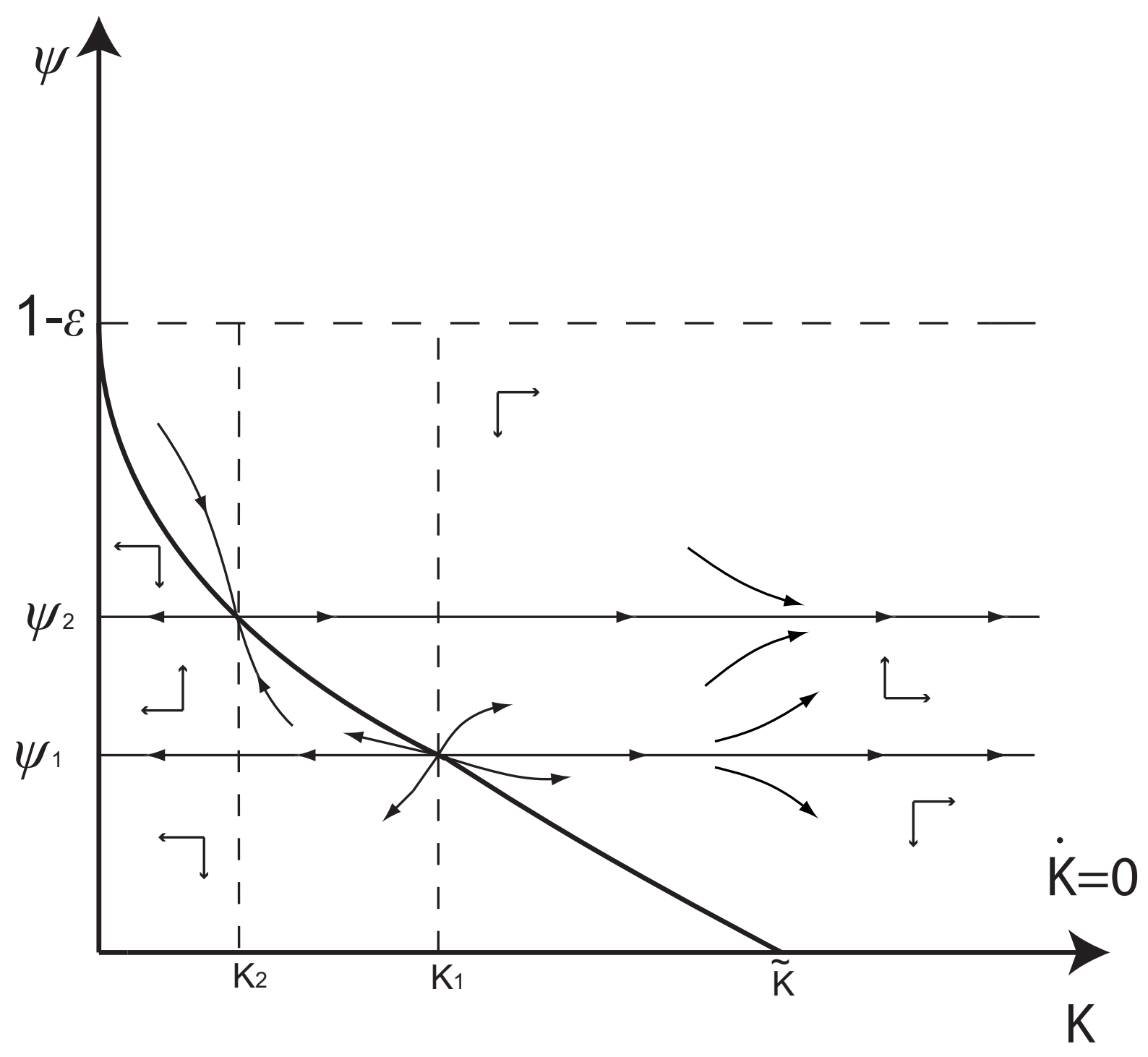


FIGURE 3

$$
\theta<1, \delta=0, \quad \psi_{2}>1-\varepsilon
$$

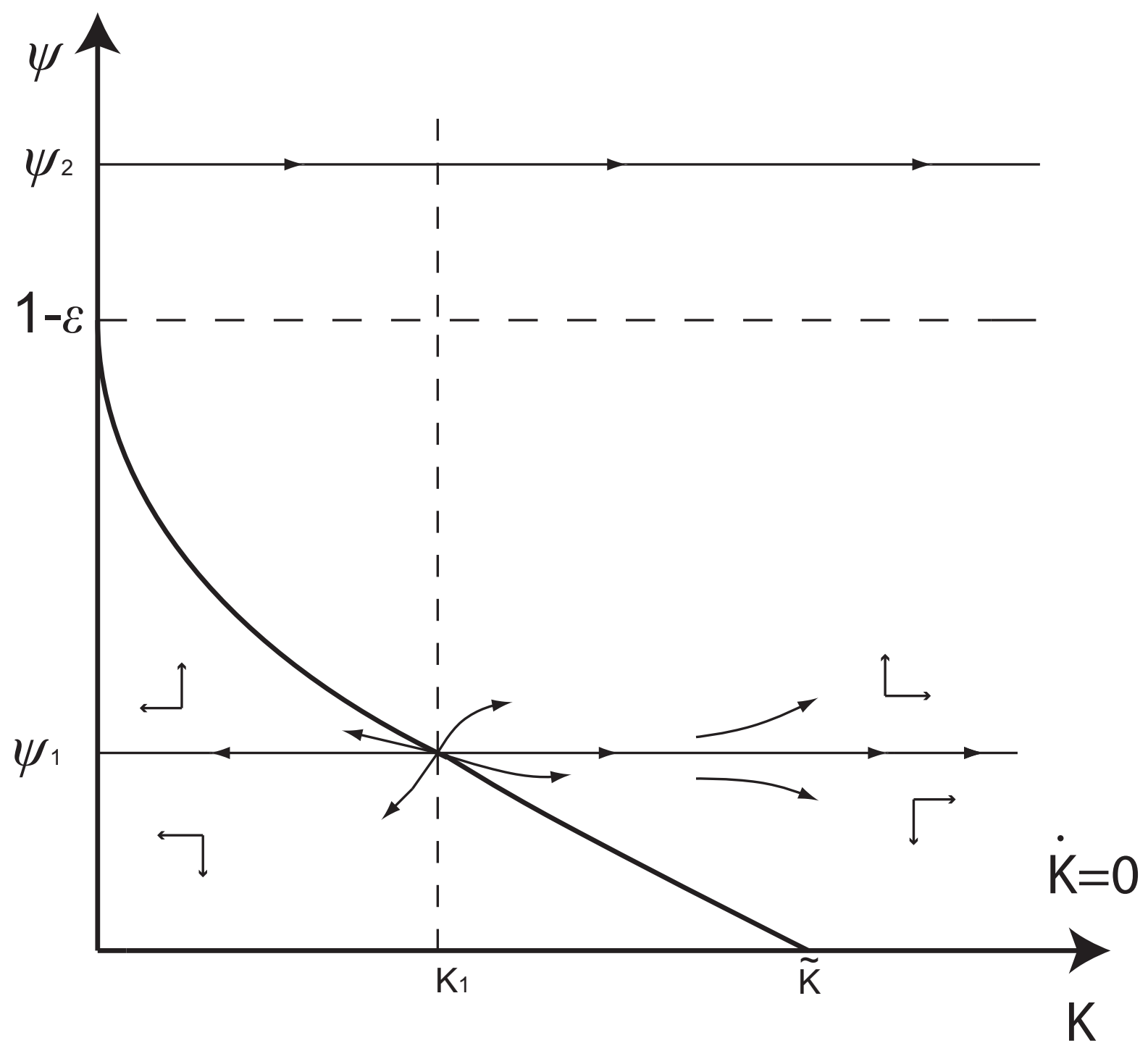


FIGURE 4

$\theta=1, \delta>0$

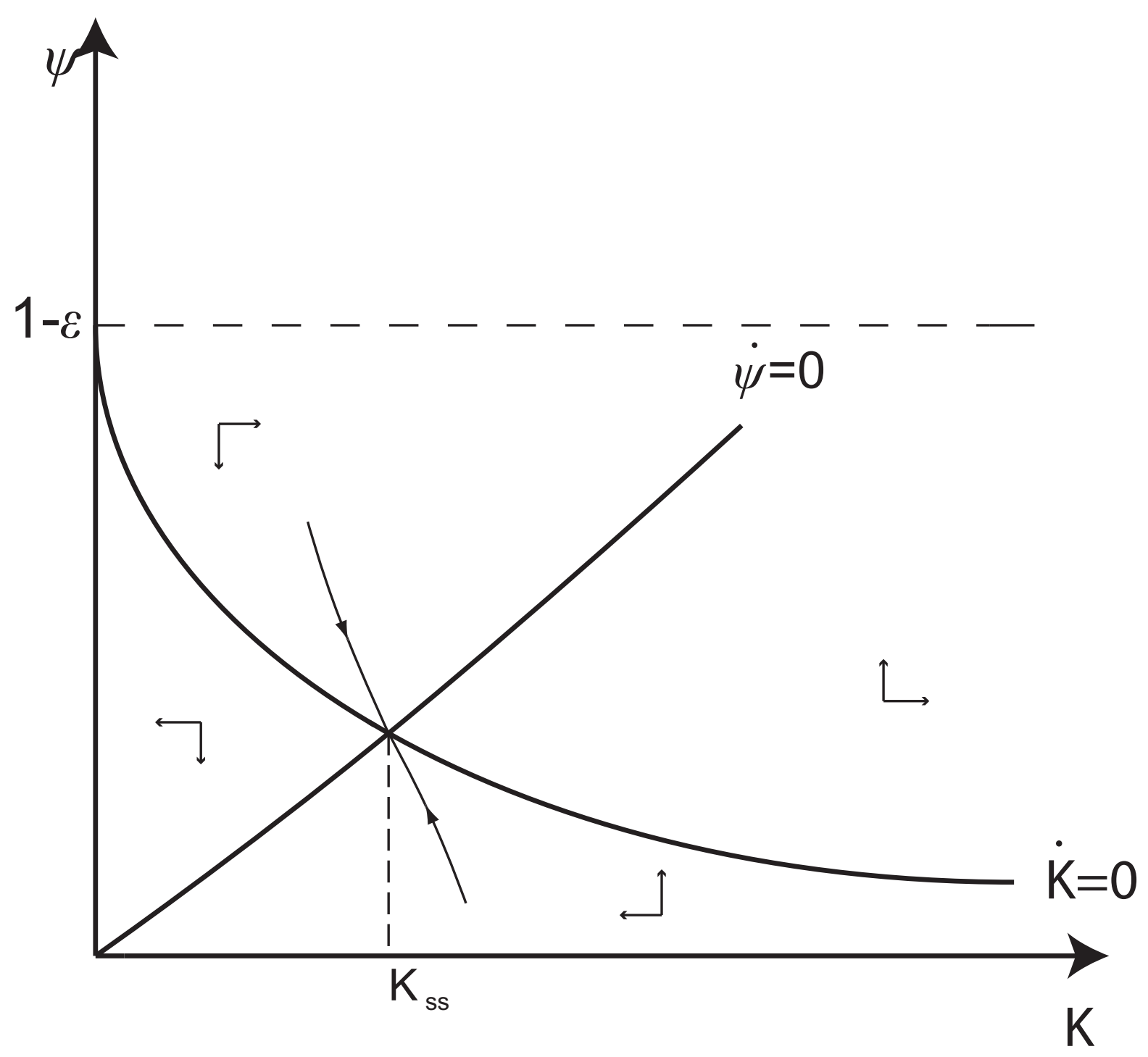


FIGURE 5

$\theta<1, \delta<0$

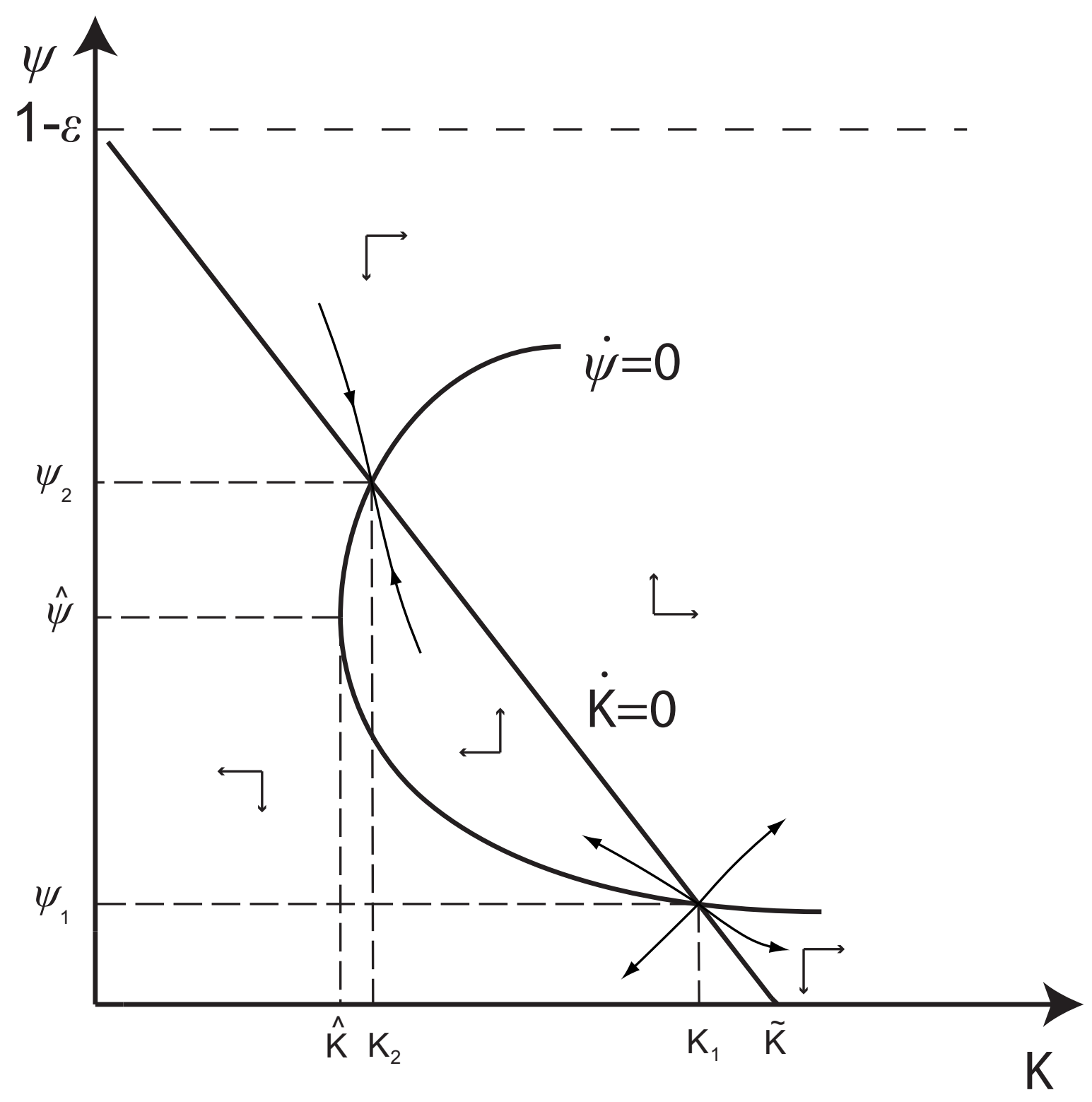




\section{CESifo Working Paper Series}

(for full list see www.cesifo.de)

1186 Jean-Pierre Ponssard, Rent Dissipation in Repeated Entry Games: Some New Results, May 2004

1187 Pablo Arocena, Privatisation Policy in Spain: Stuck Between Liberalisation and the Protection of Nationals' Interests, May 2004

1188 Günter Knieps, Privatisation of Network Industries in Germany: A Disaggregated Approach, May 2004

1189 Robert J. Gary-Bobo and Alain Trannoy, Efficient Tuition Fees, Examinations, and Subsidies, May 2004

1190 Saku Aura and Gregory D. Hess, What's in a Name?, May 2004

1191 Sjur Didrik Flåm and Yuri Ermoliev, Investment Uncertainty, and Production Games, May 2004

1192 Yin-Wong Cheung and Jude Yuen, The Suitability of a Greater China Currency Union, May 2004

1193 Inés Macho-Stadler and David Pérez-Castrillo, Optimal Enforcement Policy and Firms' Emissions and Compliance with Environmental Taxes, May 2004

1194 Paul De Grauwe and Marianna Grimaldi, Bubbles and Crashes in a Behavioural Finance Model, May 2004

1195 Michel Berne and Gérard Pogorel, Privatization Experiences in France, May 2004

1196 Andrea Galeotti and José Luis Moraga-González, A Model of Strategic Targeted Advertising, May 2004

1197 Hans Gersbach and Hans Haller, When Inefficiency Begets Efficiency, May 2004

1198 Saku Aura, Estate and Capital Gains Taxation: Efficiency and Political Economy Consideration, May 2004

1199 Sandra Waller and Jakob de Haan, Credibility and Transparency of Central Banks: New Results Based on Ifo's World Economicy Survey, May 2004

1200 Henk C. Kranendonk, Jan Bonenkamp, and Johan P. Verbruggen, A Leading Indicator for the Dutch Economy - Methodological and Empirical Revision of the CPB System, May 2004 
1201 Michael Ehrmann, Firm Size and Monetary Policy Transmission - Evidence from German Business Survey Data, May 2004

1202 Thomas A. Knetsch, Evaluating the German Inventory Cycle - Using Data from the Ifo Business Survey, May 2004

1203 Stefan Mittnik and Peter Zadrozny, Forecasting Quarterly German GDP at Monthly Intervals Using Monthly IFO Business Conditions Data, May 2004

1204 Elmer Sterken, The Role of the IFO Business Climate Indicator and Asset Prices in German Monetary Policy, May 2004

1205 Jan Jacobs and Jan-Egbert Sturm, Do Ifo Indicators Help Explain Revisions in German Industrial Production?, May 2004

1206 Ulrich Woitek, Real Wages and Business Cycle Asymmetries, May 2004

1207 Burkhard Heer and Alfred Maußner, Computation of Business Cycle Models: A Comparison of Numerical Methods, June 2004

1208 Costas Hadjiyiannis, Panos Hatzipanayotou, and Michael S. Michael, Pollution and Capital Tax Competition within a Regional Block, June 2004

1209 Stephan Klasen and Thorsten Nestmann, Population, Population Density, and Technological Change, June 2004

1210 Wolfgang Ochel, Welfare Time Limits in the United States - Experiences with a New Welfare-to-Work Approach, June 2004

1211 Luis H. R. Alvarez and Erkki Koskela, Taxation and Rotation Age under Stochastic Forest Stand Value, June 2004

1212 Bernard M. S. van Praag, The Connexion Between Old and New Approaches to Financial Satisfaction, June 2004

1213 Hendrik Hakenes and Martin Peitz, Selling Reputation When Going out of Business, June 2004

1214 Heikki Oksanen, Public Pensions in the National Accounts and Public Finance Targets, June 2004

1215 Ernst Fehr, Alexander Klein, and Klaus M. Schmidt, Contracts, Fairness, and Incentives, June 2004

1216 Amihai Glazer, Vesa Kanniainen, and Panu Poutvaara, Initial Luck, Status-Seeking and Snowballs Lead to Corporate Success and Failure, June 2004

1217 Bum J. Kim and Harris Schlesinger, Adverse Selection in an Insurance Market with Government-Guaranteed Subsistence Levels, June 2004 
1218 Armin Falk, Charitable Giving as a Gift Exchange - Evidence from a Field Experiment, June 2004

1219 Rainer Niemann, Asymmetric Taxation and Cross-Border Investment Decisions, June 2004

1220 Christian Holzner, Volker Meier, and Martin Werding, Time Limits on Welfare Use under Involuntary Unemployment, June 2004

1221 Michiel Evers, Ruud A. de Mooij, and Herman R. J. Vollebergh, Tax Competition under Minimum Rates: The Case of European Diesel Excises, June 2004

1222 S. Brock Blomberg and Gregory D. Hess, How Much Does Violence Tax Trade?, June 2004

1223 Josse Delfgaauw and Robert Dur, Incentives and Workers' Motivation in the Public Sector, June 2004

1224 Paul De Grauwe and Cláudia Costa Storti, The Effects of Monetary Policy: A MetaAnalysis, June 2004

1225 Volker Grossmann, How to Promote R\&D-based Growth? Public Education Expenditure on Scientists and Engineers versus R\&D Subsidies, June 2004

1226 Bart Cockx and Jean Ries, The Exhaustion of Unemployment Benefits in Belgium. Does it Enhance the Probability of Employment?, June 2004

1227 Bertil Holmlund, Sickness Absence and Search Unemployment, June 2004

1228 Klaas J. Beniers and Robert Dur, Politicians' Motivation, Political Culture, and Electoral Competition, June 2004

1229 M. Hashem Pesaran, General Diagnostic Tests for Cross Section Dependence in Panels, July 2004

1230 Wladimir Raymond, Pierre Mohnen, Franz Palm, and Sybrand Schim van der Loeff, An Empirically-Based Taxonomy of Dutch Manufacturing: Innovation Policy Implications, July 2004

1231 Stefan Homburg, A New Approach to Optimal Commodity Taxation, July 2004

1232 Lorenzo Cappellari and Stephen P. Jenkins, Modelling Low Pay Transition Probabilities, Accounting for Panel Attrition, Non-Response, and Initial Conditions, July 2004

1233 Cheng Hsiao and M. Hashem Pesaran, Random Coefficient Panel Data Models, July 2004

1234 Frederick van der Ploeg, The Welfare State, Redistribution and the Economy, Reciprocal Altruism, Consumer Rivalry and Second Best, July 2004 
1235 Thomas Fuchs and Ludger Woessmann, What Accounts for International Differences in Student Performance? A Re-Examination Using PISA Data, July 2004

1236 Pascalis Raimondos-Møller and Alan D. Woodland, Measuring Tax Efficiency: A Tax Optimality Index, July 2004

1237 M. Hashem Pesaran, Davide Pettenuzzo, and Allan Timmermann, Forecasting Time Series Subject to Multiple Structural Breaks, July 2004

1238 Panu Poutvaara and Andreas Wagener, The Invisible Hand Plays Dice: Eventualities in Religious Markets, July 2004

1239 Eckhard Janeba, Moral Federalism, July 2004

1240 Robert S. Chirinko, Steven M. Fazzari, and Andrew P. Meyer, That Elusive Elasticity: A Long-Panel Approach to Estimating the Capital-Labor Substitution Elasticity, July 2004

1241 Hans Jarle Kind, Karen Helene Midelfart, Guttorm Schjelderup, Corporate Tax Systems, Multinational Enterprises, and Economic Integration, July 2004

1242 Vankatesh Bala and Ngo Van Long, International Trade and Cultural Diversity: A Model of Preference Selection, July 2004

1243 Wolfgang Eggert and Alfons J. Weichenrieder, On the Economics of Bottle Deposits, July 2004

1244 Sören Blomquist and Vidar Christiansen, Taxation and Heterogeneous Preferences, July 2004

1245 Rafael Lalive and Alois Stutzer, Approval of Equal Rights and Gender Differences in Well-Being, July 2004

1246 Paolo M. Panteghini, Wide vs. Narrow Tax Bases under Optimal Investment Timing, July 2004

1247 Marika Karanassou, Hector Sala, and Dennis J. Snower, Unemployment in the European Union: Institutions, Prices, and Growth, July 2004

1248 Engin Dalgic and Ngo Van Long, Corrupt Local Government as Resource Farmers: The Helping Hand and the Grabbing Hand, July 2004 